\title{
Effect of Preparation Program on Anxiety Level of Children Undergoing Endoscopy
}

\author{
Eman S A ${ }^{1}$, Youssria E Y ${ }^{2}$, Nagla H Abu Faddan ${ }^{3}$ Naglaa A ${ }^{4}$ \\ ${ }^{1}$ Pediatric Nursing, Faculty of Nursing-Assiut University, Egypt \\ ${ }^{2}$ Pediatric Nursing, Faculty of Nursing-Sohag University, Egypt \\ ${ }^{3}$ Pediatric Department, Faculty of Medicine- Assiut University, Egypt. \\ ${ }^{4}$ Psychiatric Nursing, Faculty of Nursing-Assiut University, Egypt
}

\begin{abstract}
Like adults, children often experience anxiety associated with medical procedures.
Aim: to assess the effect of psychological preparation program on anxiety of children undergoing endoscopy. Method:- A true experimental research design (pre-test post-test control design) was used for this study. The study was conducted in Pediatric endoscopy unit at Assiut university children hospital, Egypt. A total of 70 children were enrolled in this study divided into two groups (study and control groups with 35 children in each group). Three tools were used to collect data in this study: Tool I: A structured questionnaire. Tool II: state trait anxiety inventory (STAI). Tool III: The psychological preparation program consisted of demonstration of materials that would be encountered during the procedure.
\end{abstract}

Results: the anxiety state mean score had reduced in the study group compared to that in the control group after implementation of the program and after implementation of the program compared to that before its implementation in the study group (32.80 \pm 4.64 Vs. $45.17 \pm 6.75$ and $48.09 \pm 6.97$ Vs. $32.80 \pm 4.64$, respectively) $p$ - value 0.000. for both.

Conclusion: A significant reduction of anxiety level was apparent for children undergoing endoscopy procedure after receiving the preparation program.

Keywords: anxiety, children, endoscopy, Psychological preparation program

\section{Introduction}

Pediatric gastroenterology has established itself as a subspecialty in several countries of the European Union. The most frequently used procedures for assessing and diagnosing affections of the gastrointestinal tract are esophagogastroduodenoscopy (EDS) and colonoscopy [1].

Endoscopy is a safe and widely used procedure for diagnosis and treatment purposes. While the developments in the endoscopy systems increase the image quality, the most important component affecting the quality of the procedure is patient compliance. One of the most important factors that impact patient compliance is the patient's anxiety level before the procedure [2]. High levels of anxiety before the procedure lead to low patient compliance and a difficult and uncomfortable procedure. As a result, the procedure may not be completed if performed without sedation, or if sedation is used, there may be a need for higher doses of sedatives and thus an increased risk for sedative-related complications [3].

Anxiety refers to a complex sequence of cognitive, affective, and behavioral events that are evoked by some certain stresses [4]. This psychological impact can affect not only a child undergoing medical procedures, but also the entire family. The intense anxiety and fear may result in poor cooperation, longer duration of the procedures, increased dosage of sedation, and even inadvertent complications. With the advent of new technologies, pediatric gastrointestinal endoscopy is increasingly involved in both diagnostic and therapeutic options for children with gastrointestinal problems. Apart from the well recognized serious complications of gastrointestinal endoscopy, such as bleeding, perforation, and infection, this procedure also produces discomfort, anxiety, and dissatisfaction [5]. Therefore, it is of importance for any child undergoing endoscopy to be adequately informed prior to the procedure.

The aim of the present study was to evaluate the benefit of detailed systematic information using a set of real photograph-based technical demonstration and video in addition to real visualizing of instruments by children, on the level of their anxiety before performing endoscopy.

\section{Significance of the study:}

Previous research has shown that children need to be psychologically well prepared before undergoing stressful medical procedures [6,7]. Proper psychological preparation of the child before a colonoscopy increases the child's understanding of the procedure and reduces stress on both the child and parents, hence the need for this research [8]. 


\section{Aim of the study:}

The aim of this study was to assess the effect of psychological preparation program on reducing anxiety level of children undergoing endoscopy.

\section{Research Hypotheses:}

- Children who underwent psychological preparation before endoscopy will have less anxiety level than children who will have the routine care (control group).

- Older children will have less anxiety score than younger ones. (Negative correlation may be present between age of child and anxiety score).

\section{Subjects And Method}

2.1 Research design: true experimental research design (pre-test post-test control design); this design suited the aim of the study.

\subsection{Setting:}

The study was conducted in Pediatric endoscopy unit at Assiut university children hospital.

\subsection{Sample:}

A convenient sample was obtained. Sample size was calculated as Precision Levels $10 \%$, Where Confidence Level is $95 \%$ and $\mathrm{P}=.5$. A total of 70 children who were randomly assigned to one of the two groups (35 children for each group); group 1 (study group) subjected to a psychological preparation program in addition to the routine preparation provided by Pediatric Gastroentrologist and group 2 (control group) consisted of patients who received only the routine preparation before endoscopy by the pediatric gastroenterologist at the time of the clinic visit.

2.4 Inclusion criteria: children aged from 6 to 18 years who were prepared for either upper or lower endoscopy.

2.5 Exclusion criteria: children with past experience of undergoing endoscopy, mentally retarded children, and children required the procedure to be performed under general anesthesia or if they were neurologically impaired and unable to complete the questionnaire.

\subsection{Tools of the study:}

Three tools were used for this study:

Tool I: A structured questionnaire sheet was developed by the researchers after reviewing the relevant literature which included three parts:

Part one included child's age, sex, residence, school level, parental education and occupation.

Part two: included history of drug used, history of concomitant disease, history of operations.

Part three: included data about diagnosis, type of endoscopy, indication and history of having heard about other people's experience regarding endoscopy.

Tool II: STAI-State (STAI-S) and STAI-Trait (STAI-T) are two different pen and pencil tests, answered by the individual. Both scales were used in the study. STAI-S, evaluates how the person feels within the conditions he/she is in at the present moment, and the other one, STAI-T, evaluates how the individual feels in general. The scale was developed by Spielberger (1970) [9]. STAI-S and STAI-T comprise 20 questions each, and are answered on a three likert scale ranging from rarely scored as one to mostly with a score of 3 . The Arabic version was developed by El- Beheary, 1984 [10]. STAI-S and STAI-T receive scores between 20 and 60, and higher scores are correlated with the severity of anxiety. Children with anxiety score of 45 and above had severe anxiety, those with a score of $29-44$ had moderate anxiety. While, those with a score of less than 29 had mild anxiety.

Tool III: The psychological preparation program consisted of demonstration of materials that would be encountered during the procedure (e.g., needle, syringe, and pulse oximetry devices) to acquaint children with what they would see while fully awake. The procedure (esophagogastroduodenoscopy or colonoscopy) was described by showing a book with photographs of a child undergoing the actual endoscopic procedure. Photographs were showed to the children in a stepwise fashion, from the time of the clinic visit, through the endoscopic procedure, until the time of discharge from the recovery area after endoscopy. A video was shown to children showing the steps, preparation and complications of endoscopy. Also the children were permitted to see the endoscopy room, the endoscope, and the screen.

Internal validity was assured in this research by ensuring that both study and control groups were matchable prior to the intervention (no significant differences were found between both groups regards residence, age, sex, child's educational level, parental education and job. 


\subsection{Method:}

1- Official permission was obtained from the manager of Assiut university children's hospital and the head of pediatric endoscopy unit to collect data from children.

2- A pilot study was done on $10 \%$ of the sample (7 patients) to test the clarity of the sheet and to estimate the time needed to fill the sheet. The necessary modifications were done (questions about how was the experiment of endoscopy like, better than or worse than the preparation and the most annoying things in the endoscopy were omitted because children were still drowsy after the endoscopy). The pilot sample was excluded from the study.

3- Content validity for tool I was obtained by the five juries who are experts in the field of pediatric nursing and gastroentrologists. Content validity index (CVI) was 0.92. Cronbach's Alpha revealed high reliability which is 0.822 . While, reliability and validity of tool II were determined previously.

4- Patients in both groups completed the Spielberger State-Trait Anxiety Inventory (STAI); the Arabic form at the waiting time before the endoscopy procedure and again just before the endoscopic procedure (Spielberger, 1970).

5- After the procedure, the attending gastroenterologist who was blinded to patient randomization completed a questionnaire about diagnosis and type of endoscope. To assist in maintaining the blinded status of the attending physician, they were prohibited from talking with the patient before the procedure other than to introduce themselves.

In this research design, selection and testing represents threat to the internal validity of the study. For selection, random selection of subjects into study or control groups eliminate this threat, moreover, the study and control groups were matchable in pretest score (before implementation of the program). To control the threat of testing, avoiding words such as "good" and "that's right" after a child's response helped to avoid these threats.

\subsection{Ethical considerations:}

1- Approval of research ethics committee of faculty of Nursing to commit the study.

2- A written consent was obtained from mother's of studied children to collect the data after explaining purpose and the nature of the study.

3- Children and their parents were reassured that no harm will happen to them and they had the right to refuse to participate in the study or withdraw at any time without affecting the treatment plan.

\subsection{Statistics and data analysis:}

Data were coded and analyzed using SPSS version 20. Descriptive analyses were conducted to determine the frequency distributions of the study variables. Pearson's Product Moment Correlation Coefficients were calculated to assess the relationship among the study variables. Differences between groups were tested using $\mathrm{X}^{2}$ and student $\mathrm{t}$ - test.

\section{Results}

Table (1): Demographic characteristics of participating children

\begin{tabular}{|c|c|c|c|c|c|}
\hline & \multicolumn{2}{|c|}{$\begin{array}{r}\text { Study } \\
(n=35)\end{array}$} & \multicolumn{2}{|c|}{$\begin{array}{r}\text { Control } \\
(n=35)\end{array}$} & \multirow[t]{2}{*}{ P-value } \\
\hline & No. & $\%$ & No. & $\%$ & \\
\hline \multicolumn{5}{|l|}{ Age: } & \multirow[t]{3}{*}{0.473} \\
\hline$<12$ years & 15 & 42.9 & 18 & 51.4 & \\
\hline$\geq 12$ years & 20 & 57.1 & 17 & 48.6 & \\
\hline \multicolumn{5}{|l|}{ Sex: } & \multirow[t]{3}{*}{0.467} \\
\hline Male & 22 & 62.9 & 19 & 54.3 & \\
\hline Female & 13 & 37.1 & 16 & 45.7 & \\
\hline \multicolumn{5}{|l|}{ Residence: } & \multirow{3}{*}{0.454} \\
\hline Rural & 24 & 68.6 & 21 & 60.0 & \\
\hline Urban & 11 & 31.4 & 14 & 40.0 & \\
\hline \multicolumn{5}{|l|}{ Child's educational level: } & \multirow[t]{4}{*}{0.849} \\
\hline Primary & 17 & 48.6 & 16 & 45.7 & \\
\hline Preparatory & 7 & 20.0 & 9 & 25.7 & \\
\hline Secondary & 11 & 31.4 & 10 & 28.6 & \\
\hline \multicolumn{6}{|l|}{ Father's education: } \\
\hline Illiterate/ R \& W & 10 & 28.6 & 7 & 20.0 & 0.403 \\
\hline Basic education & 1 & 2.9 & 6 & 17.1 & 0.111 \\
\hline Secondary & 14 & 40.0 & 12 & 34.3 & 0.621 \\
\hline University & 10 & 28.6 & 10 & 28.6 & 0 \\
\hline \multicolumn{6}{|l|}{ Mother's education: } \\
\hline Illiterate or read and write & 10 & 28.6 & 8 & 22.9 & 0.584 \\
\hline
\end{tabular}


Effect of Preparation Program on Anxiety Level of Children Undergoing Endoscopy

\begin{tabular}{|l|r|r|r|r|r|}
\hline Basic education & 4 & 11.4 & 4 & 11.4 & 0 \\
\hline Secondary & 14 & 40.0 & 16 & 45.7 & 0.629 \\
\hline University & 7 & 20.0 & 7 & 20.0 & 0 \\
\hline Father's job: & & & & & \\
\hline Worker & 5 & 14.3 & 8 & 22.9 & 0.356 \\
\hline Farmer & 10 & 28.6 & 7 & 48.6 & 0.403 \\
\hline Employee & 15 & 42.9 & 17 & 0.6 & 0.707 \\
\hline Skilled worker & 5 & 14.3 & 3 & & 0.771 \\
\hline Mother working condition: & & & & 22.9 & \\
\hline Working & 28 & 80.0 & 27 & 77.1 & \\
\hline Not working & & & &
\end{tabular}

Table (1) shows the demographic characteristics of participating children. There were no significant differences between study and control groups regarding age, sex, residence, child's educational level, father and mother educational level and parents working conditions.

Table (2): Distribution of participating children according to their clinical data:

\begin{tabular}{|c|c|c|c|c|c|}
\hline & \multicolumn{2}{|c|}{$\begin{array}{r}\text { Study } \\
(n=35)\end{array}$} & \multicolumn{2}{|c|}{$\begin{array}{r}\text { Control } \\
(n=35)\end{array}$} & \multirow[t]{2}{*}{ P-value } \\
\hline & No. & $\%$ & No. & $\%$ & \\
\hline Hearing about endoscopy: & & & & & \multirow[t]{3}{*}{0.470} \\
\hline Yes & 14 & 40.0 & 17 & 48.6 & \\
\hline No & 21 & 60.0 & 18 & 51.4 & \\
\hline Type of endoscopy: & & & & & \multirow[t]{3}{*}{$0.042 *$} \\
\hline Upper endoscopy & 19 & 54.3 & 13 & 37.1 & \\
\hline Lower endoscopy & 16 & 45.7 & 22 & 62.9 & \\
\hline \multicolumn{6}{|l|}{ Cause of endoscopy: } \\
\hline 1- Rectal bleeding & 10 & 28.6 & 16 & 45.8 & 0.131 \\
\hline 2- $\quad$ Chronic diarrhea & 7 & 20.0 & 9 & 25.7 & 0.569 \\
\hline 3- $\quad$ Abdominal pain & 11 & 31.4 & 6 & 17.1 & 0.163 \\
\hline 4- $\quad$ Hematemesis & 11 & 31.4 & 7 & 20.0 & 0.274 \\
\hline \multicolumn{6}{|l|}{ Results of endoscopy: } \\
\hline $1-\quad$ Normal & 7 & 20.0 & 5 & 14.3 & 0.526 \\
\hline 2- $\quad$ Esophageal problems & 5 & 14.3 & 6 & 17.1 & 0.743 \\
\hline 3- $\quad$ Gastric problems & 9 & 25.7 & 3 & 8.6 & 0.057 \\
\hline 4- $\quad$ Duodenal problems & 14 & 40.0 & 21 & 60.0 & 0.094 \\
\hline
\end{tabular}

Table (2): shows distribution of participating children according to their clinical data: No significant differences were found between study and control groups regarding hearing about endoscopy. The majority of children in both study and control groups did not hear about endoscopy. More than half of children in study group had upper endoscopy compared to nearly two-fifths of children in the control group $(\mathrm{p}=0.042)$.

Figure 1: Percentage distribution of type of endoscopy among studied sample in both study and control groups

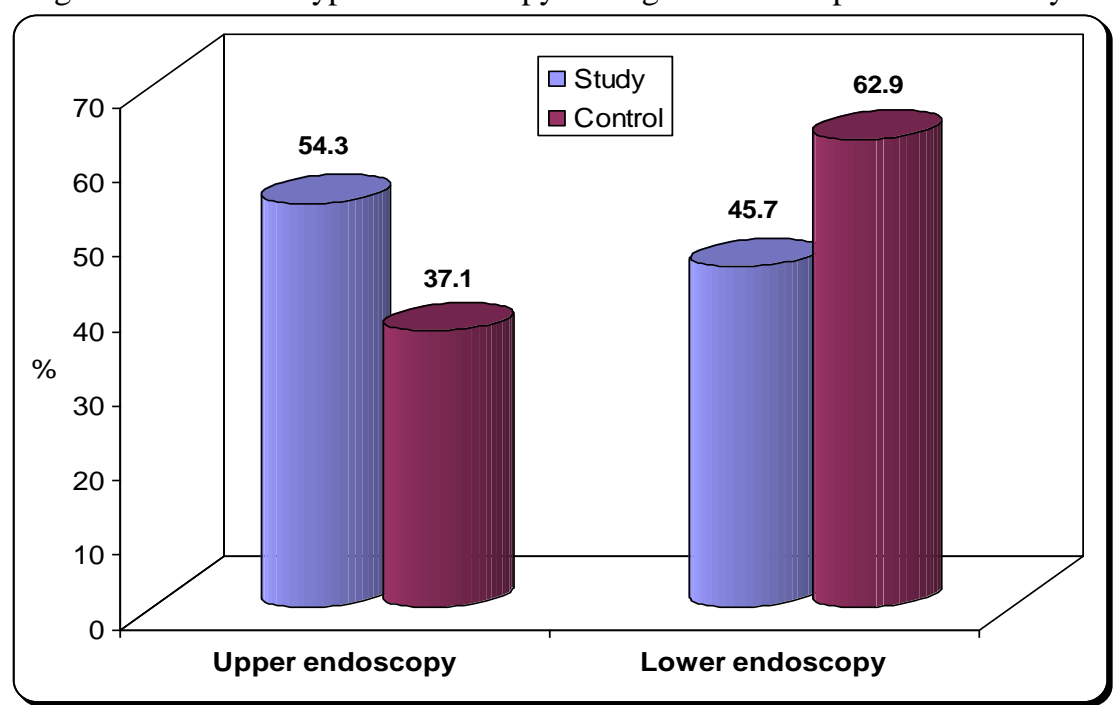




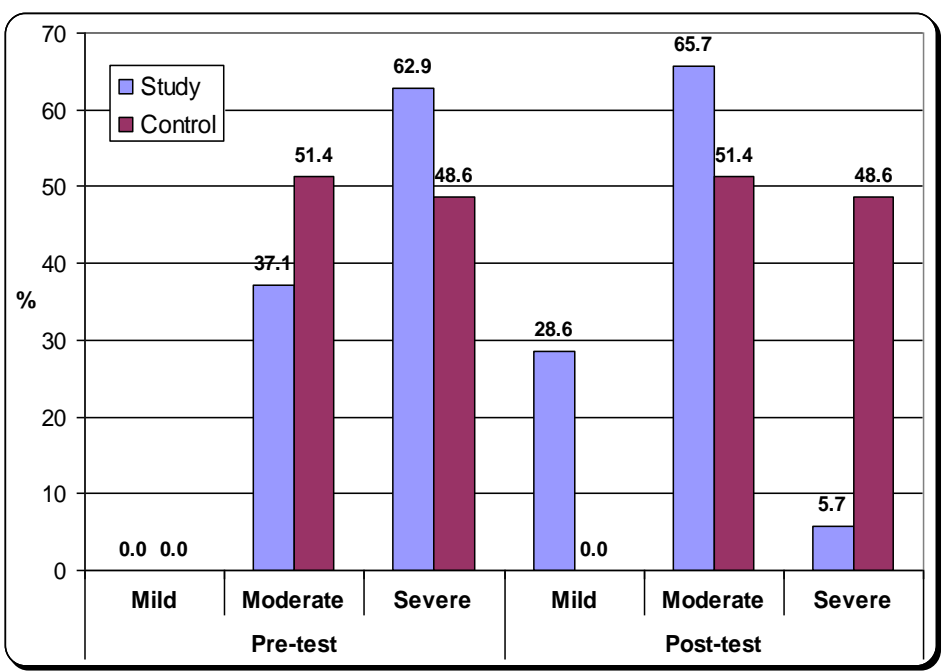

Figure (2): Percentage distribution of levels of anxiety state among study and control groups

Table (3): Mean score of anxiety state and trait among the study and control groups at pre and post-tests

\begin{tabular}{|c|c|c|c|}
\hline & $\begin{array}{r}\begin{array}{r}\text { Study } \\
(\mathbf{n}=\mathbf{3 5})\end{array} \\
\end{array}$ & $\begin{array}{r}\text { Control } \\
(\mathrm{n}=\mathbf{3 5})\end{array}$ & P-value \\
\hline \multicolumn{4}{|l|}{ Anxiety state: } \\
\hline Pre-test: & & & \multirow[t]{3}{*}{0.127} \\
\hline Mean \pm SD & $48.09 \pm 6.97$ & $45.40 \pm 6.84$ & \\
\hline Range & $36.0-60.0$ & $37.0-60.0$ & \\
\hline Post-test: & & & \multirow[t]{4}{*}{$0.000^{*}$} \\
\hline Mean \pm SD & $32.80 \pm 4.64$ & $45.17 \pm 6.75$ & \\
\hline Range & $26.0-46.0$ & $36.0-60.0$ & \\
\hline P-value & $0.000^{*}$ & 0.873 & \\
\hline \multicolumn{4}{|l|}{ Anxiety trait: } \\
\hline Mean \pm SD & $42.26 \pm 7.68$ & $43.00 \pm 7.92$ & 0.846 \\
\hline Range & $23.0-54.0$ & $32.0-60.0$ & \\
\hline
\end{tabular}

Table (3): illustrates mean score of anxiety state and trait among study and control groups pre and post implementation of the program. No significant differences were found between both groups regarding anxiety trait and state pre implementation of the program (the two groups were matchable regarding anxiety trait and state pre implementation of the program). However, a highly significant difference was found between study and control groups regarding the anxiety state mean score after implementation of the program and between the study group before and after implementation of the program ( $32.80 \pm 4.64$ vs. $45.17 \pm 6.75$ and $48.09 \pm 6.97$ vs. $32.80 \pm 4.64$, respectively ) ( $\mathrm{p}=0.000$ for both).

Table (4): Correlation between anxiety state and trait among study and control groups at pre and post- tests

\begin{tabular}{|l|r|r|r|r|}
\hline \multirow{2}{*}{ Anxiety state } & \multicolumn{3}{|r|}{ Anxiety trait } \\
\cline { 2 - 5 } & & Pre-test & \multicolumn{2}{r|}{ Post-test } \\
\cline { 2 - 5 } & r-value & P-value & r-value & P-value \\
\hline Study & 0.009 & 0.959 & -0.046 & 0.792 \\
\hline Control & $\mathbf{0 . 6 1 2}$ & $\mathbf{0 . 0 0 0 *}$ & $\mathbf{0 . 5 9 8}$ & $\mathbf{0 . 0 0 0}$ \\
\hline
\end{tabular}

Table (4): shows correlation between anxiety state and trait among study and control groups at pre and post tests. A significant positive correlation was found between anxiety state and trait in the control group during the pre and post- tests ( $\mathrm{r}=0.612$ and 0.598 , respectively, $\mathrm{p}$ - value 0.000 for both).

Table (5): Correlations of age with anxiety state and anxiety trait among participating children

\begin{tabular}{|l|l|r|r|}
\hline \multirow{2}{*}{ Study } & & \multicolumn{2}{|c|}{ Age (years) } \\
\cline { 3 - 4 } & Anxiety state & 0.137 & P-value \\
\cline { 2 - 4 } & Anxiety trait & 0.192 & 0.431 \\
\hline \multirow{2}{*}{ Control } & Anxiety state & $\mathbf{0 . 3 7 7}$ & 0.420 \\
\cline { 2 - 4 } & Anxiety trait & 0.114 & $\mathbf{0 . 0 2 6} *$ \\
\hline
\end{tabular}

Table (5) presents correlations of age with anxiety state and anxiety trait among participating children. A positive significant correlation between anxiety state and age of children in the control group $(0.377, \mathrm{p}$ - value 0.03$)$. However, no significant correlations were found between anxiety state and trait with age in the study group. 
Table (6): Correlation of Anxiety state with type of endoscopy among study and control groups at pre and posttests

\begin{tabular}{|l|l|r|r|r|}
\hline \multirow{4}{*}{ Group } & & \multicolumn{2}{c|}{ Pype of endoscopy } & \multirow{2}{*}{ P-value } \\
\cline { 3 - 5 } & & Upper endoscopy & Lower endoscopy & \\
\cline { 3 - 5 } Study & Pre-test & Mean \pm SD & Mean \pm SD & \\
\cline { 2 - 5 } & Post-test & $50.05 \pm 7.14$ & $45.75 \pm 6.18$ & 0.061 \\
\hline \multirow{2}{*}{ Control } & Pre-test & $33.74 \pm 4.43$ & $31.69 \pm 4.77$ & 0.072 \\
\cline { 2 - 5 } & Post-test & $46.08 \pm 7.15$ & $45.00 \pm 6.79$ & 0.719 \\
\hline
\end{tabular}

Table (6) illustrates correlation of anxiety state with type of endoscopy among study and control groups at pre and post-tests. No significant correlations were found between pre-test or post-test and type of endoscopy in the study and control groups.

Fig (1) shows percentage distribution of type of endoscopy among studied sample in both study and control groups. Upper endoscopy represents more than half of children in the study group compared to more than one third in the control group (54.3\% Vs. 37.1\%, respectively). However, less than half of children in the study group underwent lower endoscopy $45.7 \%$ compared to less than two thirds in the control group (62.9\%).

Fig (2): presents percentage distribution of levels of anxiety state among study and control groups. Children with severe anxiety state in the study group were significantly decreased from $62.9 \%$ in the pretest to only $5.7 \%$ in the posttest.

\section{Discussion}

This study aimed to assess the effect of preparation program on anxiety level of children undergoing endoscopy. When a child requires an invasive medical procedure such as gastrointestinal endoscopy, the entire family may experience feelings of anxiety. Such anxiety may be unnecessarily increased by lack of information, misinformation, or erroneous preconceived notions. Children, in particular, need information to help them separate reality from fantasy. If enough information is not provided to the child for him or her to understand what is happening during endoscopy, he or she may become emotionally overwhelmed. Strong emotions such as anxiety, fear, and anger can render the child unable to cooperate with medical personnel, which in turn can lead to more consuming of sedations. [11]

Psychological techniques focus on alleviating the anxiety associated with invasive medical procedures. Cognitive-behavioral preparation (filmed or photographed modeling, breathing exercises) has been effective in reducing anxiety in pediatric patients undergoing surgery. [12].

Our study found that the mean score of anxiety state was significantly reduced in the study group at the posttest compared to that of the pretest ( $\mathrm{p}$ - value 0.000). Moreover, a significantly difference of mean score of anxiety state of the study group between pre and posttest (p-value 0.000 ) as shown in table 3 . This is the same line with Riddhiputra \& Ukarapol, 2006 [13] who stated that preparation program has reduced the level of anxiety in children over 5 years of age. In addition, Claar et al., 2002 [14] reported in their study that the level of anxiety in children with knowledge about upper endoscopy has decreased toward future procedures.

Tanaka et al., 2011 [8] and Berkenbosch, 2015[15] suggested that it is logically for the level of anxiety to be decreased in older children undergoing endoscopy by psychological preparation provided to them.

The majority of studied children had moderate to severe anxiety before endoscopy (as shown in figure 2). This is in accordance with Hagiwara et al., 2015 [16] who reported that $80 \%$ of patients were anxious before endoscopy. Moreover this is the case in adult not only children as stated by McEntire et al., 2013 [17]

Studies involving psychological preparation programs before surgical procedures have shown similar results. Fernandes et al., 2014 [18] concluded that children who received educational material before surgery were significantly less worried than those of the control group. Wakimizu et al., 2008 [19] implemented at-home psychological preparation programme for children and family prior to surgery and reported significantly lower anxiety score of study children compared to those of control group. However, Fincher et al., 2011[20] who reported that preoperative preparation intervention had no effect on child's anxiety.

A significant positive correlation between anxiety state and trait in the control group before and after the intervention ( $\mathrm{r}=0.612$ and 0.589 , respectively) as shown in table 4 . This can be interpreted by the fact that personal characteristic affect children undergoing medical procedure as endoscopy. Children in the control group were already anxious as shown by their anxiety trait which was provoked and exaggerated by endoscopy as shown by anxiety state.

The present study showed no significant correlation between anxiety trait and age of children in both study and control groups. However, a significant positive correlation between anxiety state and age of children in the control group $(\mathrm{r}=0.377$, $\mathrm{p}$ - value: 0.03 ). This can be explained by the fact that older children were more knowledgeable about endoscopy, hence more anxious. However, cognitive level of younger children was limited result in less understanding of the meaning of endoscopy and so, little anxiety. Also Perry et al., 
2012[21] reported that children are most susceptible to the stress of surgery owing to their limited cognitive capabilities, greater dependence on others, lack of self control, limited life experience, and poor understanding of the health care system.

\section{Conclusion}

Preparatory intervention using systematic video illustration of the technical procedures in children undergoing gastrointestinal endoscopy could significantly reduce the children's anxiety. There is significant positive correlation between anxiety state and trait in the control group before and after the intervention.

\section{Based on this study, it was recommended that}

\section{Recommendation}

- Training program for nurses to learn them about psychological preparation of children undergoing endoscopy.

- Strategies reducing stress and anxiety should be part of the preparation of children before upper and lower endoscopy.

- Further researches needed on the effect of different strategies on reducing anxiety and stress in children undergoing endoscopy.

\section{References}

[1]. S Diaconescu, G. Paduraru, C .Olaru, N. Gimiga, C. Soponaru, A. Ciubara, M . Bolat, and M. Iorga, Pre-procedual recommendations in pediatric gastrointestinal endoscopy, Romanian Journal of Pediatrics, LXIV, (4), (2015).

[2]. H UNAL, J. Ozcurumez , S. Saritafi, M. Korkmaz, and H. Selcuk, Which factors affect anxiety level before upper gastrointestinal endoscopy?, Endoscopy, 20(3), 2012: 67-71.

[3]. A Hayes, M. Buffum, E. Lanier, E. Rodahl, and C. Sasso, A music intervention to reduce anxiety prior to gastrointestinal procedures, Gastroenterol Nurs, 26 2003: 145-9.

[4]. C Spielberger, Theory and research on anxiety. In: C Spielberger, editor. Anxiety and behavior New York: Academic Press; 1966: 3-20.

[5]. D Drossman, L.Brandt, C. Sears, Z. Li, J. Nat, and E. Bozymki, A preliminary study of patients' concerns related to GI endoscopy. Am J Gastroenterol, 91, 1996: 287-91.

[6]. H . Larsen, C. Heilmann, C. Johansen., and L. Adamsen, An analysis of parental roles during haematopoietic stem cell transplantation their offspring: A qualitative and participant observational study, Journal of Advanced Nursing, 67(7), (2011), 1458-1467. doi:10.1111/j.1365-2648.2010.05587.x

[7]. T. Pelander, \& H. Leino-Kilpi, Children's best and worst experiences during hospitalisation, Scandinavian Journal of Caring Sciences, 24(4), (2010), 726-733. doi:10.1111/ j.1471-6712.2010.00770.x

[8]. K Tanaka, N. Oikawa, R. Terao, Y. Negishi, T. Fujii, T. Kudo, and T. Shimizu, Evaluations of psychological preparation for children undergoing endoscopy, Journal of pediatric gastroenterology and nutrition, 52(2), (2011), 227-229. doi:10.1097/MPG.0b013e3181f25f57

[9]. C. Spielberg, Manual for state-trait anxiety inventory, Consulting Psychologists Press, California 1970.

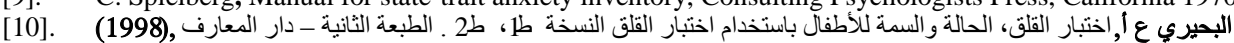

[11]. M Lori, W. Robert, S. Rita, K. Marsha et al, The Effects of a Psychological Preparation Program on anxiety in children and adolescents undergoing Gastrointestinal Endoscopy. Pediatric Gastroenterology \& Nutrition, 27 (2), (1998), $161-165$.

[12]. G Hong, Z. Lixia, H.William, W. Wang et al, A randomized controlled trial of the effectiveness of a therapeutic play intervention on outcomes of children undergoing inpatient elective surgery: study protocol, Journal of Advanced Nursing 70(2), (2013), 431442. doi: 10.1111/jan.12234.

[13]. P. Riddhiputra, N. Ukarapol, Effect of Systematic Psychological Preparation Using Visual Illustration Prior to Gastrointestinal Endoscopy on the Anxiety of Both Pediatric Patients and Parents, J Med Assoc Thai, 89 (2) , 2006, 231-5

[14]. R Claar, L. Walker, and J. Barnard, Children's knowledge, anticipatory anxiety, procedural distress, and recall of esophagogastroduodenoscopy, J Pediatr Gastroenterol Nutr, 342002, 68-72.

[15]. J Berkenbosch, Options and Considerations for Procedural Sedation in Pediatric Imaging, Pediatric Drugs, 17(5), (2015), 385399.

[16]. S Hagiwara, U. Nakayama, M. Tagawa, K. Arai et al, Pediatric patient and parental anxiety and impressions related to initial gastrointestinal endoscopy: A Japanese multicenter questionnaire Study. Hindawi Publishing Corporation Scientifica Volume 2015, http://dx.doi.org/10.1155/2015/797564

[17]. J. McEntire, J. Sahota, T. Hydes, and T. M. Trebble, An evaluation of patient attitudes to colonoscopy and the importance of endoscopist interaction and the endoscopy environment to satisfaction and value, Scandinavian Journal of Gastroenterology, 48( 3), 2013, pp. 366-373.

[18]. S. Fernandes, P. Arriaga and F. Esteves, Providing preoperative information for children undergoing surgery, a randomized study testing different types of educational material to reduce children's preoperative worries, Health education research, 29, (6), 2014

[19]. R Wakimizu, S. Kamagata, T. Kuwabara, and K. Kamibeppu, A randomized controlled trial of an at-home preparation programme for Japanese preschool children: effects on children's and caregivers' anxiety associated with surgery, Journal of Evaluation in Clinical Practice, ISSN 1356-1294. 2008.

[20]. W Fincher, J. Shaw, and A. Ramelet, The effectiveness of a standardized preoperative preparation in reducing child and parent anxiety: a single-blind randomised controlled trial, Journal of Clinical Nursing, 21, (2012), 946-955, doi: 10.1111/j.13652702.2011.03973.x

[21]. J Perry, V. Hopper, Masiongale, Reduction of Preoperative Anxiety in Pediatric Surgery Patients Using Age-Appropriate Teaching Interventions, American Society of PeriAnesthesia Nurses , (2012), 1089-9472/\$36.00 doi:10.1016/j.jopan.2012.01.003 